\title{
Ekstraksi Asam Oksalat Pada Umbi Porang (Amorphophallus Oncophyllus) dengan Metode Mechanical Separation
}

\author{
Martha R. Sitompul, Fidianto Suryana dan Donny S. Bhuana, Mahfud \\ Departemen Teknik Kimia, Fakultas Teknologi Industri, Institut Teknologi Sepuluh Nopember (ITS) \\ e-mail:mahfud@chem-eng.its.ac.id
}

\begin{abstract}
Abstrak-Umbi Porang (Amorphophallus Oncophyllus) adalah umbi porang yang memiliki kandungan asam oksalat yang tinggi yang dapat menimbulkan iritasi dan gatal apabila dikonsumsi namun memiliki kandungan glukomannan yang sangat bermanfaat. Tujuan dari penelitian ini adalah untuk mengetahui proses ekstraksi asam oksalat pada umbi porang (Amorphophallus Oncophyllus) dengan metode mechanical separation. Adapun metode yang dilakukan yaitu penggilingan chip porang, melakukan pengayakan, melakukan analisa di mikroskop dan melakukan proses titrasi. Dari hasil proses titrasi, asam oksalat yang dihasilkan kemudian dianalisis yield dan recovery nya. Yield dan Recovery tertinggi yang didapatkan sebesar $\mathbf{2 4 , 9 8 9 4 \%}$ dan $\mathbf{8 6 , 1 1 7 3 \%}$ dari mesh 100 menggunakan pelarut natrium bicarbonate, sedangkan untuk pengujian sifat fisik dilakukan melalui analisa mikroskop cahaya didapatkan kandungan asam oksalat yang ditandai dengan terbentuknya morfologi jarum kristal.
\end{abstract}

Kata Kunci-Umbi porang (Amorphophallus Oncophyllus), asam oksalat, mechanical separation.

\section{PENDAHULUAN}

$\mathrm{U}$ MBI Porang merupakan salah satu kekayaan alam yang dimiliki Indonesia. Tidak banyak yang mengenal umbi porang sebagai bahan pangan lokal yang banyak tumbuh di lahan hutan di Jawa Timur. Porang (Amorphophallus Oncophyllus) adalah salah satu jenis tanaman iles-iles yang tumbuh dalam hutan. Porang merupakan tumbuhan semak (herba) yang berumbi di dalam tanah. Umbi porang berpotensi memiliki nilai ekonomis yang tinggi, karena mengandung glukomanan yang baik untuk kesehatan dan dapat dengan mudah diolah menjadi bahan pangan tetapi juga mengandung asam oksalat yang tidak baik jika dikonsumsi. Porang (Amorphophallus oncophyllus) merupakan tanaman lokal yang dikembangkan di Indonesia [1]. Manfaat iles-iles terutama di bidang industri dan kesehatan, karena kandungan glukomannan pada tepung umbinya. Iles-iles merupakan jenis tanaman umbi yang mempunyai potensi dan prospek untuk dikembangkan di Indonesia [2]. Jenis A.Oncophyllus ini awalnya ditemukan di Kepulauan Andaman India, menyebar kearah timur melalui Myanmar masuk ke Thailand dan Indonesia [3].
Asam oksalat adalah senyawa kimia yang memiliki rumus $\mathrm{H}_{2} \mathrm{C}_{2} \mathrm{O}_{4}$ yang biasanya digambarkan dengan rumus HOOC$\mathrm{COOH}$. Asam oksalat ini merupakan as am organik yang relative kuat 10.000 kali lebih kuat dari pada asam asetat [4]. Konsumsi makanan yang mengandung asam oksalat dapat menyebabkan kristalisasi dalam ginjal dan gangguan gangguan kesehatan lainnya. Kandungan asam oksalat mempunyai fungsi sebagai asam pencuci untuk menghilangkan kotoran kemudian untuk melapisi logam stainless stell, nickel alloy, kromium dan titanium Industri tekstil, industri kimia lainnya digunakan untuk membuat seluloid, rayon, bahan warna, tinta, bahan kimia dalam fotografi, pemurnian gliserol, dibidang obat-obatan dapat dipakai sebagai hemostatik dan anti septik luar. Namun, umbi porang belum dimanfaatkan oleh industri di Indonesia atau masyarakat secara luas serta produksi asam oksalat di Indonesia yang belum memenuhi kebutuhan.

Pada umumnya untuk metode ekstraksi dan purifikasi asam oksalatdan glukomannan hampir sama namun yang telah banyak dilakukan pada ekstraksi glukomannan.Asam oksalat dapat dikstraksi baik dengan cara mekanik (proses kering) atau cara basah (proses kimia). Proses kering dilakukan dengan penggilingan irisan umbi menjadi tepung porang dan selanjutnya dimurnikan dengan wind-sifting [5]. Namun demikian, tepung porang yang diperoleh dengan cara ini menghasilkan kemurnian yang rendah dan dijual sebagai bahan pangan dengan harga rendah [6]. Sedangkan proses basah dapat dilakukan dengan menggunakan timbal asetat, garam (misalnya aluminium sulfat) [7]

\section{URAIAN PENELITIAN}

\section{A. Bahan yang Digunakan}

Bahan utama yaitu chip porang (Amorphophallus Oncophyllus). yang diperoleh dari Nganjuk, Jawa Timur. Natrium bicarbonate 1,1904 M, aquades dan $\mathrm{KMnO}_{4}$ 0,0892 N.

\section{B. Prosedur Penelitian}

1. Pembuatan Tepung porang. dengan menggunakan disk mill. Memasukkan chip porang kedalam disk mill untuk digiling agar diperoleh tepung porang. Tepung porang kemudian diayak menggunakan vibrating screen untuk mendapatkan mesh 60,80 dan 100 yang akan digunakan sebagai variable dalam penelitian ini. Kemudian melakukan 
uji analisa morfologi asam oksalat dengan menggunakan mikroskop cahaya.
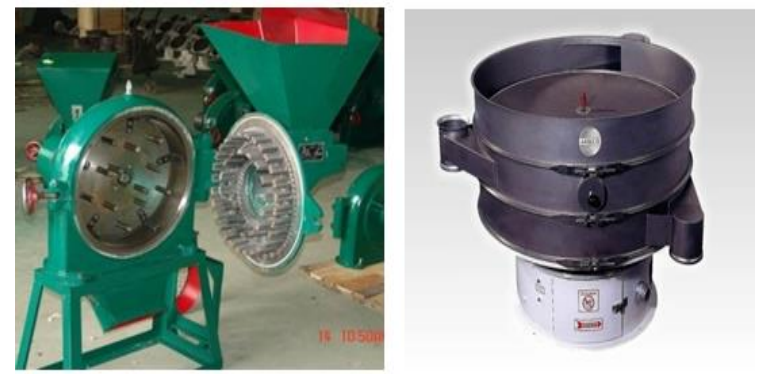

Gambar 1. Peralatan ekstraksi Mechanical Separation

2. Proses Titrasi.dengan menggunakan peniter potasium permanganate $\left(\mathrm{KMnO}_{4}\right)$. Menimbang tepung porang sebanyak 5 gram kemudian ditambahkan pelarut Natrium bicarbonate $200 \mathrm{ml}$. Dilakukan proses pemanas an selama 15 menit. Memisahkan filtrar dan endapannya dengan menggunakan centrifuge. Filtrat yang diperoleh kemudian ditambahan asam sulfat $\left(\mathrm{H}_{2} \mathrm{SO}_{4}\right)$ sebanyak $5 \mathrm{ml}$ kemudian langsung dilakukan proses titrasi. Proses titrasi dikatakan sudah selesai apabila larutan tersebut nantinya akan mengalami perubahan warna menjadi merah muda yang tidak akan hilang selama 30 detik.

Kemudian dihitung kadar oksalat menggunakan rumus sebagai berikut :

$$
\text { Kadar Oksalat }=\frac{\text { Volume }(\mathrm{ml}) \times \mathrm{NKMnO}_{4} \times \text { BE Oksalat }}{\text { Massa Porang (gram) }} \times 100
$$

\section{Variabel Penelitian}
1. Ukuran (Mesh) : 60,80 dan 100
2. Ratio F/S (gr/mL) : $0,05,0,10$ dan 0,15

\section{Analisis Sampel}

Asam oksalat yang dihasilkan dihitung yield dan recovery serta dianalsis dengan mikroskop cahaya.

\section{HASIL PENELITIAN DAN PEMBAHASAN}

\section{A. Penentuan Yield dan Recovery Asam Oksalat}

Pada penelitian ini, untuk mendapatkan Yield dan Recovery asam oksalat sebelumnya harus dilakukan proses titrasi. Pada dasarnya, tujuan titrasi dilakukan untuk menentukan titik equivalent, yaitu titik dimana titrasi mencapai setara secara stoikiometri.

Pada penelitian ini proses titrasi tidak menggunakan indikator. Dimana ini termasuk jenis titrasi redoks yang menggunakan potasium permanganat (merah muda/ungu) sebagai peniter tidak membutuhkan indikator. Ketika peniter dikurangi, larutan akan menjadi tidak berwarna. Setelah mencapai titik ekivalensi, terdapat sisa peniter yang berlebih dalam larutan. Titik ekivalensi diidentifikasikan pada saat munculnya warna merah muda yang pertama (akibat kelebihan permanganat) dalam larutan yang sedang dititer.
Pada grafik dalam Gambar 2 dan 3, dapat dilihat bahwa recovery dan yield asam oksalat yang diperoleh mencapai titik tertinggi pada ukuran bahan 100 mesh sedangkan penurunan yield dan recovery pada ukuran bahan 60 mesh dikarenakan semakin besar ukuran bahan jumlah glukomanan semakin banyak. Banyaknya glukomanan mengakibatkan semakin sedikit asam oksalat yang dapat terekstrak.

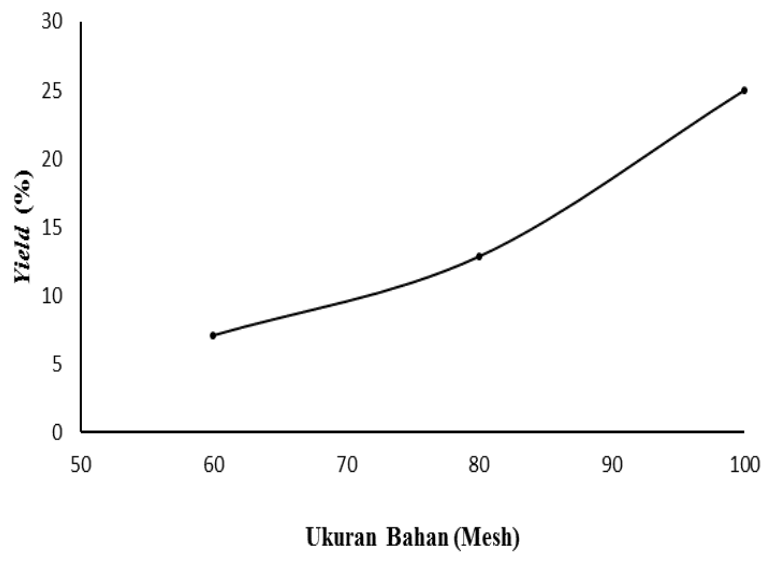

Gambar 2. Grafik pengaruh ukuran bahan (mesh) terhadap yield asam oksalat

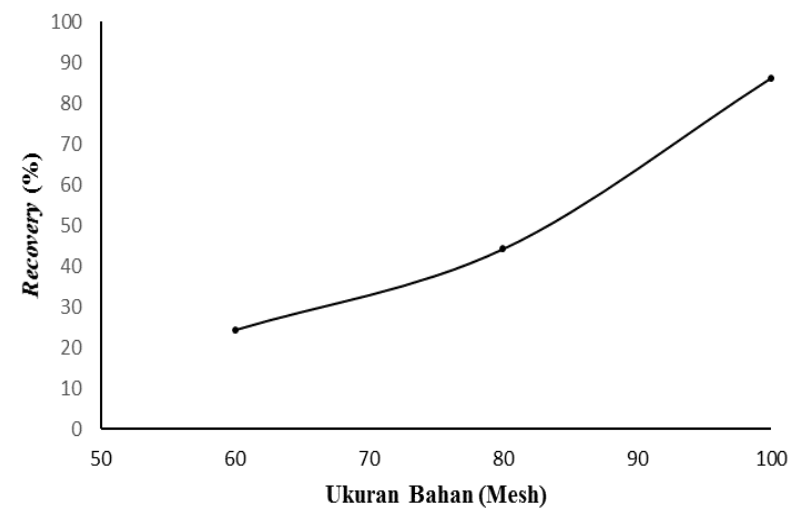

Gambar 3. Grafik pengaruh ukuran bahan (mesh) terhadap recovery asam oksalat

\section{B. Hasil Uji Analisa Mikroskop Cahaya}

Pada analisa Mikroskop cahaya, bahan yang dianalisa adalah tepung porang dengan ukuran 60, 80 dan 100 mesh dengan perbesaran 400x dimana pada tepung ini masih mengandung asam oksalat. Bentuk dari Kristal oksalat bervariasi dan umumnya dideskripsikandalam bentuk rafida (jarum), druse, stiloid, prisma, dan kristal pasir. Bentuk rafida biasanya terhimpun dalam berkas. Kristal oksalat kadang dibentuk di sel khusus yang hanya berfungsi untuk membentuk kristal. Bentuk morfologi Kristal oksalat sesuai dengan literature seperti gambar berikut : 

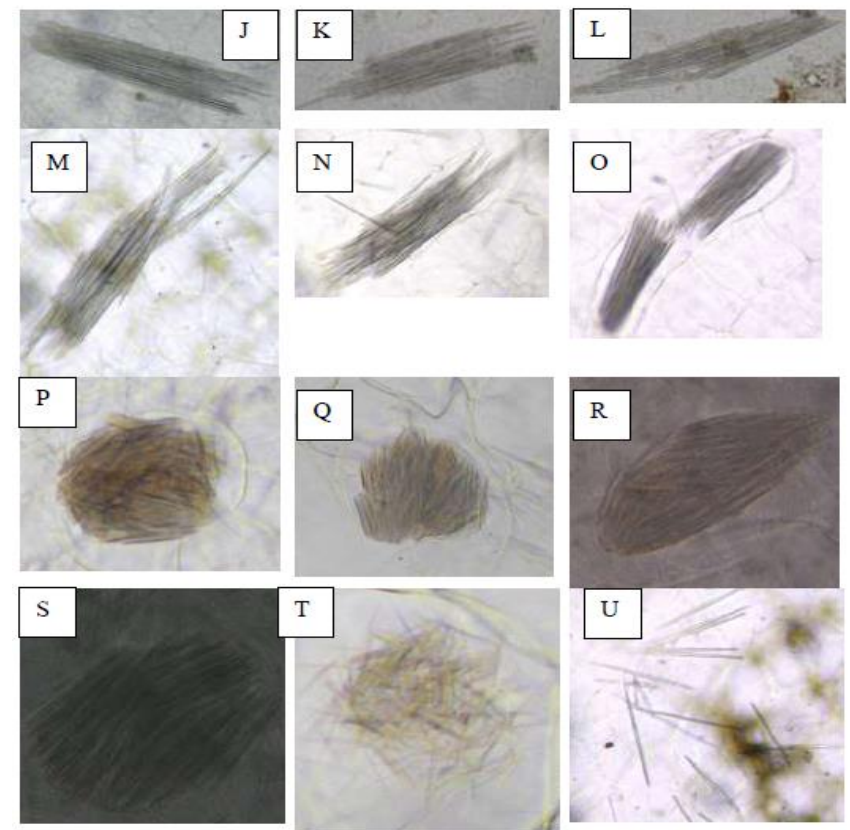

Gambar 1. Berbagai bentuk kristal kalsium oksalat yang ditemukan pada Amorphophallus

Gambar 4. Berbagai bentuk Kristal oksalat yang ditemukan pada Amorphophallus Oncophyllus

Sementara itu hasil analisa yang kami lakukan mendapatkan bentuk morfologi seperti pada literature yang ada yaitu berbentuk rafida (jarum) seperti pada gambar 5 dibawah ini.

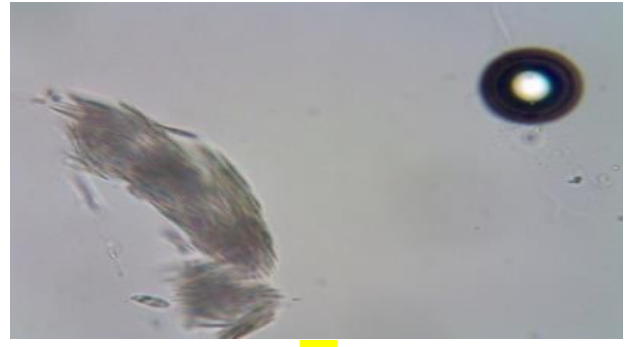

(a)

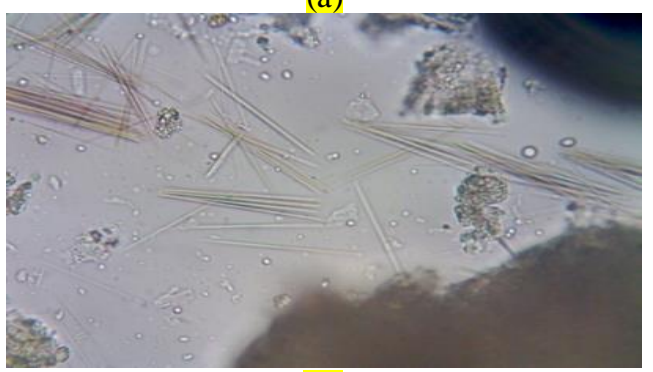

(b)

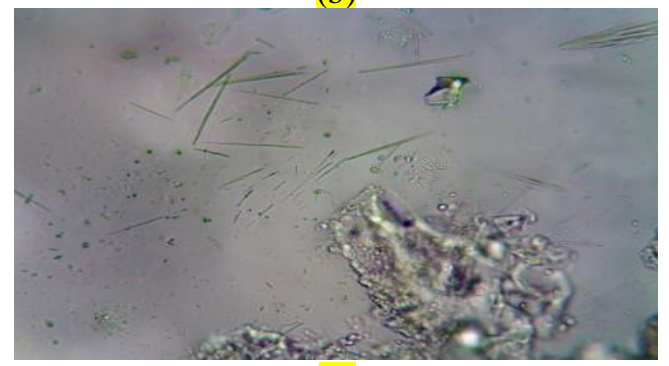

(c)

Gambar 5. Hasil analisa mikroskop cahaya dengan perbesaran $400 \mathrm{x}$ untuk (a) ukuran 60 mesh (b) ukuran 80 mesh dan (c) ukuran 100 mesh.
Berdasarkan Gambar 5 terlihat bahwa didalam umbi porang (Amorphophallus Oncophyllus) memiliki kandungan asam oksalat cukup tinggi yang sangat berbahaya bagi tubuh jika dikonsumsi, ini dibuktikan pada terlihat asam oksalat dengan bentuk jarum-jarum seperti pada gambar diatas.

\section{KESIMPULAN}

Berdasarkan hasil penelitian ini dapat disimpulkan bahwa:

1. Semakin kecilnya ukuran bahan (mesh) maka yield dan recovery yang didapatkan semakin kecil.

2. Semakin kecilnya ukuran bahan (mesh) maka recovery yang didapatkan semakin kecil

3. Hasil analisa properti fisik pada analisa mikroskop cahaya menghasilkan bentuk morfologi seperti jarum yang menandakan adanya kandungan asam oksalat

\section{DAFTAR PUSTAKA}

[1] Anonymous, Budidaya Dan Pengembangan Porang (Amorphophallus Muelleri Blume) Sebagai Salah Satu Potensi Bahan Baku Lokal. 2013.

[2] R. Mamudh, "Melihat Budidaya Iles-iles di Hutan Ketapanrame," Harian Radar Mojokerto, 2009.

[3] Sumarwoto, "Iles-iles (Amorphophallus muelleri Blume), Deskripsi dan sifat-sifat lainnya," 2005.

[4] R. . dan O. D. . Kirk, Encyclopedia of Chemical Technology. 2007.

[5] J. Parry, Konjac glucomannan. In: A. Imeson, ed. Food stabilisers, Thickeners and Gelling Agents. Singapore: WilleyBlackwell, 2010.

[6] C. Xu, W., Wang S., Ye, T., Jin, W., Liu, J., Lei, J., Li, B. and Wang, "A simple and feasible approach to purify konjac glucomannan from konjac flour - temperature effect, Food Chem," pp. 171-176, 2014.

[7] T. C. Chua M., Chan, K., Hocking, T. J., Williams, P. A., Perry, C. J. and Baldwin, "Methodologies for the extraction and analysis of konjac glucomannan from corms of Amorphophallus konjac K. Koch," Carbohydr. Polym, pp. 2202-2210, 2012. 